\title{
Interaction of Ethanol Vapour with Silane-Modified Surface of Corning Porous Glass CPG-10
}

\author{
Misael Silas Nadiye-Tabbiruka \\ Department of Chemistry, University of Botswana, Private Bag 00704 Gaborone, Botswana \\ Correspondence should be addressed to Misael Silas Nadiye-tabbiruka, nadiyem@mopipi.ub.bw
}

Received 7 September 2012; Accepted 1 October 2012

Academic Editors: H. Pal, T. Panczyk, and D. Strout

Copyright (C 2012 Misael Silas Nadiye-tabbiruka. This is an open access article distributed under the Creative Commons Attribution License, which permits unrestricted use, distribution, and reproduction in any medium, provided the original work is properly cited.

\begin{abstract}
The interaction of ethanol vapour at $293 \mathrm{~K}$ with modified Corning controlled porous glass (CPG-10) samples of various presilylation is reported. Ethanol adsorption on CPG-10 was greatly reduced by silylation to extents largely depending on the silylation extent, type of silane used, and on the concentration and accessibility of residual silanols. The obtained adsorption isotherms, BET surface areas, as well as the observed changes at the various stages during the sorption particularly in the capillary condensation region also showed similar dependence. In the capillary condensation region, in the case of the dimethyl dichlorosilane-modified sample, hysteresis type was changed from $\mathrm{H} 3$ to $\mathrm{H} 1$. On the triethyl chlorosilane-modified sample an unexpected suppression of hysteresis effects occurred with a consequent transformation of type IV to type II adsorption isotherm.
\end{abstract}

\section{Introduction}

Surface silanols and siloxanes have been classified and widely investigated because of their influence on silica surface properties, [1-5]. Surface modification replaces the surface silanol protons with bulky organic groups producing a nonpolar surface rich in large organic groups [6-8] from a formally silanol-rich polar surface. Surfaces are produced with hydrophobicity extent depending on the type, size, and concentration of the organic groups [1, 2 , 9], whose concentration also depends on the original surface silanols' concentration. This modification finds use in reducing agglomeration of silica nanoparticles [10], in chromatographic stationary phases [11-13], in purification of water [14], and in improving fragility of optical fibres that are now used in the telecommunication super highway as well as in surgical and diagnostic tools in hospitals. The consequent hydrophobicity is used in preventing corrosion of steel and magnesium articles without compromising their metal strength [15]. Porous silica modified with bithiophene tripodal ligand can be used to remove toxic heavy metals ions including $\mathrm{Hg}^{2+}, \mathrm{Cd}^{2+}, \mathrm{Pb}^{2+}, \mathrm{Cu}^{2+}, \mathrm{Zn}^{2+}, \mathrm{K}^{+}, \mathrm{Na}^{+}$, and $\mathrm{Li}^{+}$from their aqueous solutions [16].
Surface silanols have been shown to influence the interaction of alcohols with siliceous materials [17-19]. Consequently, a change in their surface concentration and accessibility will directly affect ethanol adsorption as well as the contact angle at the three phase contact line in alcohol. However, in the capillary condensation region when the surface silanols are "out of sight", the effect of modification on the interaction may vary widely depending on the modifier size and shape.

The objective of the current work is to investigate ethanol interaction with standard Corning controlled porous glass CPG-10, which is similar to vycor. A study will be made on the changes in capillary condensation behaviour of the porous glass resulting from modification using trimethylchlorosilane, TMCS, and dimethyldichlorosilane, DMDCS, which produce surfaces with compact organic groups; triethylchlorosilane (TECS), and triphenylchlorosilane (TPCS) which produce surfaces with more open organic groups. From the resulting ethanol adsorption isotherms, BET specific surface areas will be obtained for the samples. The effect of the level of compaction of the organic groups on the interaction will also be investigated by partial treatment to $1 / 4$ TMCS silylation. 


\section{Experimental}

Ethanol adsorption isotherms were obtained by measuring the equilibrium pressure and the corresponding change in mass of a pretreated CPG-10 powder of known initial weight using a vacuum microbalance, after every dose of the adsorbate to its saturation vapour pressure and back. The apparatus and procedure used in this work have been described in detail in an earlier paper [20]. The possible sources of error in the determination of the weight adsorbed (adsorption on the microbalance assembly, buoyancy, and Knudsen flow effects $[21,22]$ ) were considered and found to be negligible. Similar conditions were used in this work; consequently, these effects are negligible here as well.

\subsection{Materials}

2.1.1. CPG-10 Porous Glass. Corning controlled porous glass CPG-10 is used as a standard for porous adsorbents in studies of surface area and pore size distribution. Samples which were used as adsorbents in this work were modified using trimethyl chlorosilane (TMCS) triethyl chlorosilane (TECS) dimethyl dichlorosilane (DMDCS), and triphenyl chlorosilane (TPCS) in a similar way to that used in earlier vapour chemisorption kinetics' studies [23].

2.1.2. Ethanol. Ethanol $99.95 \%$ (BDH chemicals Ltd.) was transferred directly to a reservoir bulb without further purification to avoid contamination. It was outgassed immediately using freeze-thaw cycles [20] and then redistilled into a second reservoir bulb. It was frozen using liquid nitrogen and out-gassed with the rest of the apparatus.

2.2. Procedure. An appropriate sample of CPG-10 powder, about $200 \mathrm{mg}$, was loaded in a small glass bucket of known weight and suspended on one arm of an electronic vacuum microbalance. Details of the electronic microbalance have been given elsewhere [20]. A counterweight made from a solid glass rod, equal in weight to the combined weight of the bucket and the sample, was suspended on the other arm. Details of the evacuation of the sample, its dosing with adsorbate vapour, and the measurement of adsorption have been given elsewhere [20]. Ethanol adsorption isotherms and BET surface areas for CPG-10 were obtained before and after treatment with the relevant silanes.

\section{Results and Discussion}

Ethanol adsorption isotherms on CPG-10 samples are given as follows: Figure 1 is for unmodified sample, Figure 2 is for TMCS-modified, Figure 3 is for TECS-modified, and Figure 4 is for DMDCS-modified sample. Collected isotherms in Figure 5 are for untreated and DMDCS treated samples and those in Figure 6 are for TMCS and TECS treated samples of CPG-10 used in this work for simple comparison. Figure 7 is a cross-plot of the adsorption isotherm of untreated with that of DMDCS modified sample

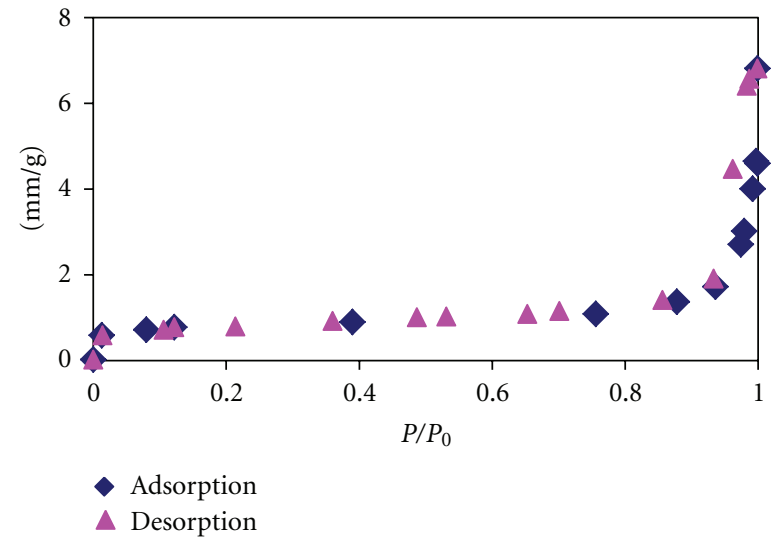

FIGURE 1: Shows the adsorption of ethanol in millimoles per gram $\left(\mathrm{mmg}^{-1}\right)$ of the adsorbent to give a type IV ethanol adsorption isotherm on untreated Corning controlled porous glass (CPG-10) at $293 \mathrm{~K}$; with a thin type $\mathrm{H} 3$ hysteresis.

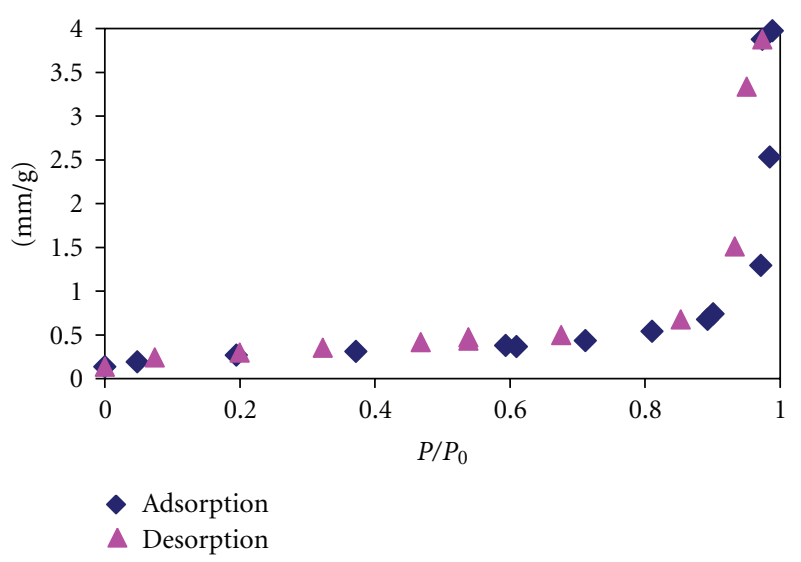

FIGURE 2: Ethanol adsorption isotherm (millimoles per gram versus $\left.P / P_{0}\right)$ for TMCS-modified CPG-10 showing the greatly reduced adsorption and the retained hysteresis type $\mathrm{H} 3$ at the higher pressure end (around $P / P_{0}=0.97$ ).

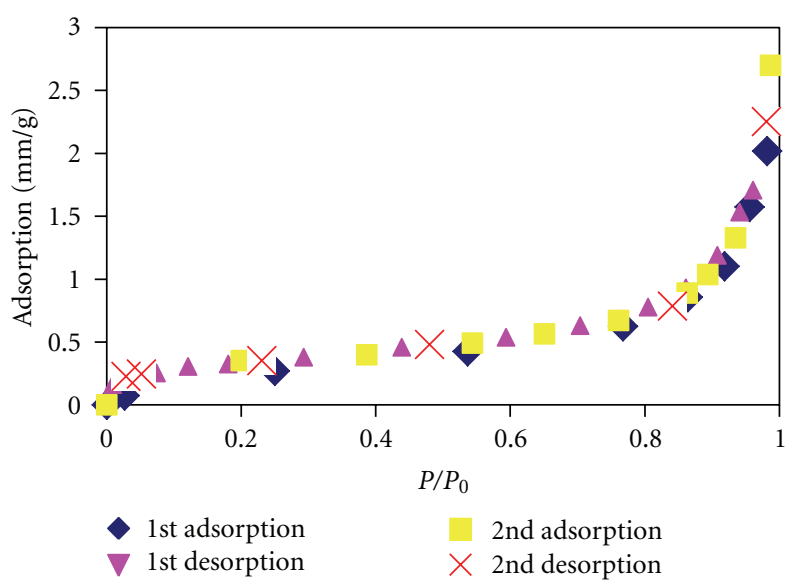

FIGURE 3: Ethanol adsorption isotherm (millimoles per gram versus $P / P_{0}$ ) for TECS-modified CPG-10 showing the change from type IV (Figure 1) to type II (Figure 3). It was scanned up and down to confirm the change. 


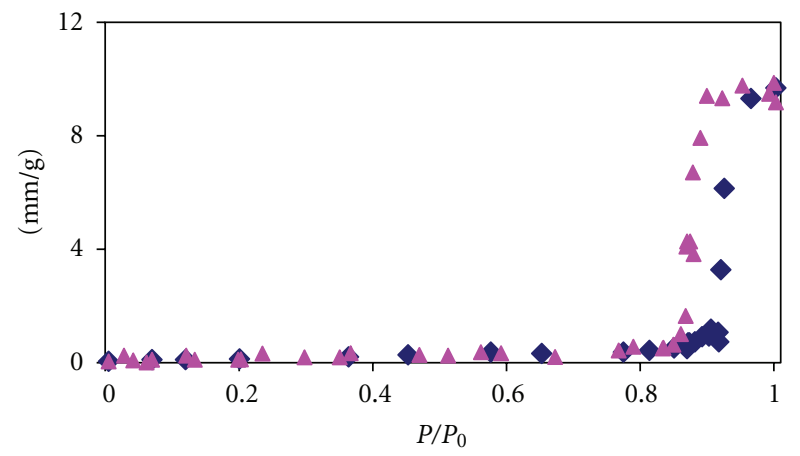

- Adsorption

$\Delta$ Desorption

FIgURE 4: Showing type IV ethanol adsorption isotherm (millimoles per gram versus $P / P_{0}$ ) on DMDCS-modified CPG-10. A clear type $\mathrm{H} 1$ hysteresis is obtained in this case from type $\mathrm{H} 3$ of the unmodified sample (Figure 1). The hysteresis loop shifts to the lower pressure end $\left(P / P_{0}=0.9\right)$ and is more asymptotic to the saturation axis $\left(P / P_{0}=1\right)$.

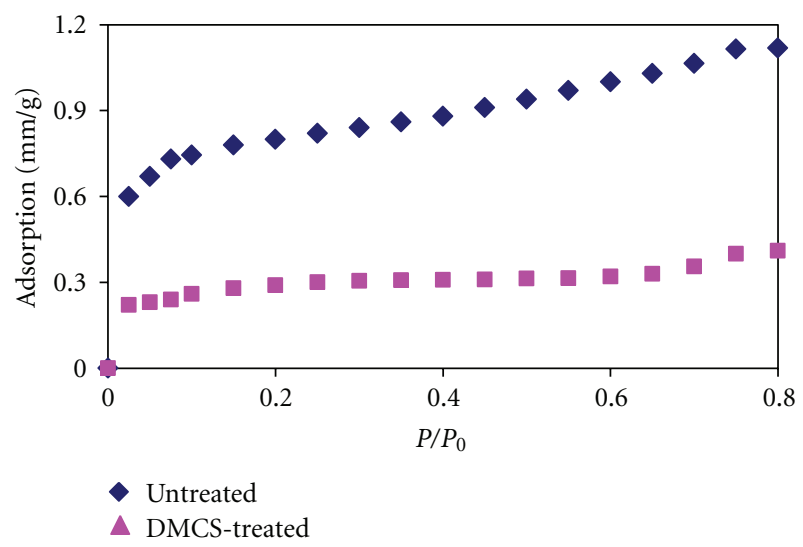

FIGURE 5: Shows coplotted isotherms (millimoles per gram versus $\left.P / P_{0}\right)$ to show the reduction in ethanol adsorption at the monolayer and multilayer regions resulting from modification of CPG-10 with DMDCS.

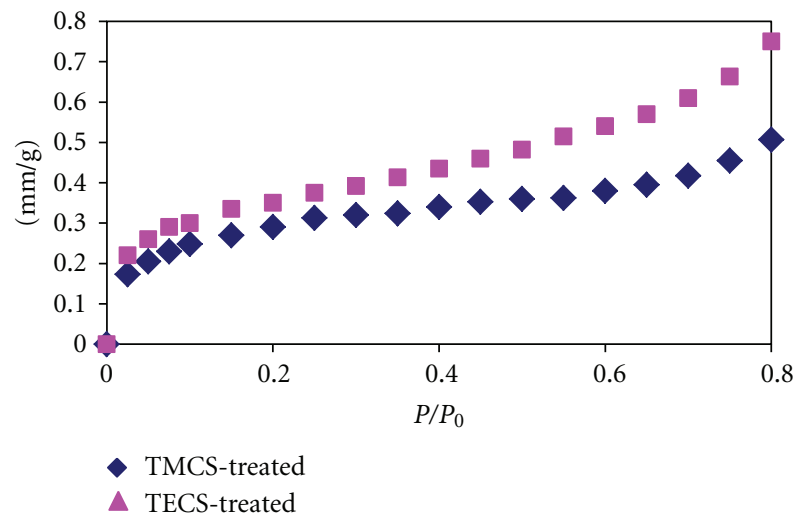

Figure 6: Shows coplotted isotherms (millimoles per gram versus $\left.P / P_{0}\right)$ to compare the effectiveness in reduction of ethanol adsorption between TMCS-treated and TECS-treated CPG-10.

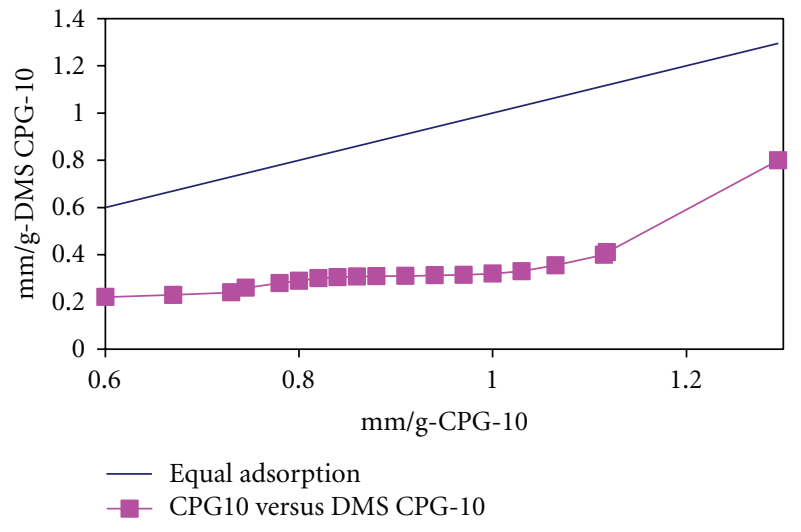

FIGURE 7: A cross-plot of ethanol adsorption isotherms (millimoles per gram unmodified versus millimoles per gram DMDCSmodified) for unmodified CPG-10 against DMDCS-modified CPG10 to reveal changes occurring. It shows the gradual multilayer adsorption increase (small slope) followed by a jump during capillary condensation (bigger slope), on the modified sample.

TABLe 1: Measured BET areas in $\mathrm{m}^{2} \mathrm{~g}^{-1}$ for CPG-10 $(d=17.5 \mathrm{~nm})$ silylated with various silanes.

\begin{tabular}{lc}
\hline Modifier silane $\{$ ET/ST K\} & $\mathrm{SA} / \mathrm{m}^{2} / \mathrm{g}$ \\
\hline NIL $\{673 \mathrm{~K}\}$ & 100.0 \\
1/4TMCS $\{673 / 673 \mathrm{~K}\}$ & 31.0 \\
TPCS $\{673 / 653 \mathrm{~K}\}$ & $(27.0)$ \\
TECS $\{673 / 653 \mathrm{~K}\}$ & 43.6 \\
DMDCS $\{673 / 653 \mathrm{~K}\}$ & $(23.6)$ \\
TMCS $\{673 / 653 \mathrm{~K}\}$ & 25.2 \\
\hline
\end{tabular}

( ) values for CPG-10 of diameter $12.5 \mathrm{~nm}$.

ET is evacuation temperature, ST is silylation temperature.

to reveal changes occurring during adsorption. Table 1 gives a summary of the determined BET surface areas.

Ethanol was chosen as an adsorbate because of its polar-organic nature so that it can gain easier access to residual hidden silanols in the modified silica samples than benzene through its stronger specific interactions with the silanols through hydrogen bonding, which is intermediate between physisorption and chemisorption. The potential complications expected here in the interpretation of BET surface area results, compared to the case of benzene [20,24], will be avoided by using the results obtained for comparative purposes only.

3.1. The Shapes of the Isotherms. Isotherms of type IV, according to the BDDT classification as revised by sing $[25,26]$, are obtained for the untreated, TMCS-treated, and DMDCS-treated CPG-10 samples. The untreated and TMCS-treated samples exhibit a type $\mathrm{H} 3$ hysteresis loop consequently, it is not possible to determine the Gurvitsch volume. The sample treated with DMDCS exhibits a type IV isotherm with a type H1 hysteresis loop. For TECS treated samples, hysteresis disappears completely, resulting in a type II isotherm. The isotherms of the untreated and the TMCS 
treated samples exhibit sharp knees, making it relatively easy in these cases to estimate the monolayer coverage. The collected adsorption isotherms in Figure 5 show that DMCS-modified CPG-10 adsorb much less ethanol than the unmodified sample; those in Figure 6 show that modification by TMCS reduces ethanol adsorption more than TECS modification. The isotherm cross-plot in Figure 7 shows a small gradual increase in adsorption of 0.1 (millimoles per gram) $\mathrm{mmg}^{-1}$ (small slope in the range $0.6 \mathrm{mmg}^{-1}$ to $1.0 \mathrm{mmg}^{-1}$ on $x$-axis) on the DMDCS-modified CPG-10. The corresponding increase (bigger slope) by the untreated sample in the monolayer and multilayer range is $0.5 \mathrm{mmg}^{-1}$. This indicates that the DMDCS-modified sample has a more uniform but "ethanophobic" external surface. In the capillary condensation region a greater increase of $0.4 \mathrm{mmg}^{-1}$ is observed for DMDCS-treated sample than the $0.2 \mathrm{mmg}^{-1}$ for the untreated sample probably due to enhancement by residual surface chlorine atoms in the pores.

3.2. The BET Surface Areas. The BET ethanol specific surface area for the untreated CPG-10 sample of pore diameter $12.5 \mathrm{~nm}$ is $100 \mathrm{~m}^{2} \mathrm{~g}^{-1}$. This is larger than, but in reasonable agreement with, the value of $85 \mathrm{~m}^{2} \mathrm{~g}^{-1}$ obtained using benzene as the adsorptive [24] (see Table 1). It seems that, in spite of fewer ethanol potential adsorption sites, more ethanol molecules are adsorbed in a monolayer than benzene probably because they have easier access to the internal pore network due to their smaller cross-sectional area.

It should be reiterated here, that ethanol, (like other alkanols) has localised adsorption on silica [27, 28] because of the strong specific interactions through hydrogen bonding between the surface silanols and the hydroxyl groups on the alcohol. This is reflected in the higher isosteric heat of adsorption value of $51.8 \mathrm{~kJ} \mathrm{~mol}^{-1}$ compared to $28.3 \mathrm{~kJ} \mathrm{~mol}^{-1}$ for benzene at half coverage and in its continued decrease with increasing coverage $[29,30]$. These indicate that the modes of adsorption of alcohols on silica, and the orientation of the alcohol molecules, change with coverage [18], resulting in a variation in the molecular cross-sectional area and hence the BET specific surface area.

3.3. Effects of Modification on Ethanol Adsorption. Modification of silica reduces ethanol adsorption by a factor depending on the type of modifier, its concentration at the surface, and the relative vapour pressure of ethanol. The trend of the surface group concentrations per $\mathrm{nm}^{2}$ of the various silanes in the absence of pores on aerosil are 1.9 for (trimethylsilyl) TMS preevacuated at $598 \mathrm{~K}=$ 1.9 for (dimethylsilyl) DMS preevacuated at $673 \mathrm{~K},>1.6$ for (triethylsilyl) TES preevacuated at $673 \mathrm{~K},>1.4$ for TMS preevacuated at $673 \mathrm{~K},>0.7$ for $1 / 4 \mathrm{TMS}$ preevacuated at $673 \mathrm{~K}$ and $>0.4$ for (triphenylsilyl) TPS preevacuated at $673 \mathrm{~K}[19,20]$. A similar trend should be expected for wide pore CPG-10 porous glass used in this work. The collected ethanol Isotherms in Figures 5 and 6 show this relative effect of modification by the various silanes on the monolayer and multilayer adsorption region on CPG-10. The resulting trend in adsorption reduction effectiveness is DMDCS > TMCS > TECS. This is also the trend of the increasing concentration of residual silanols, indicating that the concentration of available silanols is of paramount importance. The corresponding surface areas are given in Table 1. In the literature, the pore volume and BET surface areas of silicas were found to be reduced by modification in some cases [31-34], and increased in others [34]. The decrease in surface area observed in this work is by factors that depend on the type and concentration of the modifier group. The trend of the surface area is as follows: (untreated) $>$ TES-treated > DMDCS-treated > TMCS-treated. This trend is that of decreasing concentration of residual silanols (the reverse of that of the concentration of the modifier groups on aerosil given above) indicating that the trend of the surface area is identical to, once again, the trend of the concentration of the residual silanols at the surface. This confirms that the first alcohol molecules are adsorbed by hydrogen bonding [30] through the defects of the layer of modifier groups. In this way, these defects are patched up, leaving a more uniform layer of methyl groups exposed at the surface. This first adsorption on the high energy sites is reflected in the very high BET $C$ constant [20], and in the trend of isosteric enthalpy of adsorption obtained by various workers $[27,30,35]$. Specific orientation of the initial molecules adsorbed at the surface was used in explaining the behaviour of polar molecules adsorbed on alumina $[36,37]$.

3.4. Hysteresis Effects. In the capillary condensation region, ethanol adsorption shows some irreversibility, resulting in thin hysteresis loops for the untreated, the TMCS-treated, and the DMDCS-treated CPG-10 samples (see Figures 1, 2 , and 4 , resp.). However, modification of CPG-10 with TES results in a type II ethanol adsorption isotherm (see Figure 3). The pores are definitely not blocked by chemisorption of the TES groups at the entrances, because benzene adsorption in this region exhibits hysteresis effects in which a loop of type H1 is observed [24]. The Gurvitsch volume, in benzene adsorption, is only slightly affected by the TES groups (for CPG-10 pore diameter $17.5 \mathrm{~nm}$ from $1.01 \mathrm{~cm}^{3}$ unmodified to $0.93 \mathrm{~cm}^{3}$ TES-modified). In the current case, the probable explanation could be that the first ethanol molecules adsorb at the entrances of the pores, which are narrow [38] and hence have a very high adsorption potential due to the overlapping adsorption fields from opposite walls. These ethanol molecules together with the large and long ethyl chains of the silyl groups may block the narrow entrances to the pores (the reduction in $d V / d r$ and the shift of the modal pore radius to the larger radius end in the pore size distribution from benzene sorption supports this idea [39]). At higher pressure, displacement of these molecules into the pore interior by incoming molecules is probably not possible as the heats of adsorption at this stage are either equal to the heats of ethanol condensation $\left(40.5 \mathrm{~kJ} \mathrm{~mol}^{-1}\right)$ or even less [30]. Therefore, there is an energy barrier to adsorption by displacement mechanism. Further adsorption will therefore be on top of the methyl groups of the adsorbed ethanol and the ethyl chains of TES groups. The result is weaker interaction between ethanol and the modified 
surfaces, the consequence of which is an increase in the contact angle and hence a suppression of hysteresis effects.

In spite of the high contact angle in ethanol of 41 degrees [39], DMDCS-treated CPG-10 exhibits hysteresis effects. A loop of type $\mathrm{H} 1$ is observed (see Figure 4) with a Gurvitsch volume of $0.56 \mathrm{~cm}^{3} \mathrm{~g}^{-1}$. The Gurvitsch volume given on the sample bottle by the manufacturer for CPG10 of pore-diameter of $12.5 \mathrm{~nm}$ is $0.59 \mathrm{~cm}^{3} \mathrm{~g}^{-1}$; implying that modification hardly affects the volume of the pores. The small difference observed could probably be attributed to the decrease in multilayer adsorption (Figures 5 and 7), with contributions from the decrease in pore volume due to blocking of smaller pores and narrowing of the pore size distribution (as shown by a more asymptotic capillary condensation branch of the adsorption isotherm at an earlier relative pressure $P / P_{0}=0.9$, and a sudden upward turn of the cross-plot in Figure 7) just as in the case of benzene [24].

\section{Conclusions}

Ethanol adsorption on porous silica is greatly reduced by modification in both the monolayer and multilayer regions of the adsorption isotherm, to extents that depend on the surface concentration, size and type of modifier group, as well as on the concentration of residual surface silanols. Consequently, the BET specific surface area is also reduced accordingly. The trend in effectiveness of modifiers in the reduction of ethanol adsorption is DMDCS > TMCS > TECS. This is also the trend of increasing concentration of residual surface silanols, indicating that the concentration of the surface silanols is important. Modification by TPCS reduces ethanol adsorption and CPG-10 surface area but could not be compared to others as it was on a sample with lower average pore radius (see Table 1). Modification of CPG-10 by DMDCS alters the hysteresis type from $\mathrm{H} 3$ on unmodified sample to $\mathrm{H} 1$ on the modified sample. This is probably because of the efficiency of DMDCS in silanol removal together with the compact nature of the resulting DMS groups which do not block the narrow pore entrance thus allowing easier access to ethanol through into the large bellies of the pores of the modified sample. The silanols at the narrow entrances of the pores of the unmodified and partially modified samples, hydrogen-bond with ethanol molecules. In so doing, they partially block the pore entrance and thus prevent the display of a clear Gurvitch volume. This partial blocking, augmented by obstruction by the long silyl ethyl chains, together with the increased contact angle is thought to cause the disappearance of hysteresis on TECS modified samples by denying ethanol molecules easy access into the pores by either capillary condensation or adsorbate displacement mechanism.

\section{Acknowledgment}

The author wishes to acknowledge the British Commonwealth Scholarship Committee for funding this study. The contributions in various ways by Professor Julian Eastoe for laboratory space, Duncan Turling of the glass blowing workshop in the School of Chemistry at the University of Bristol, and the University of Botswana for the short study leave for this study are gratefully acknowledged.

\section{References}

[1] E. F. Vansant, P. Voort, and C. C. Vranken, Characterisation and Chemical Modification of Silica, Chapter 3 and 4, Elsevier, Amsterdam, The Netherlands, 1995.

[2] N. Hewitt, Compounding Precipitated Silica in Elastomers, William Andrews, New York, NY, USA, 2007.

[3] P. G. Hall, R. T. Williams, and R. C. T. Slade, "Nuclear magnetic resonance and dielectric relaxation investigations of water sorbed by Spherisorb silica," Journal of the Chemical Society, vol. 81, no. 4, pp. 847-855, 1985.

[4] D. R. Halfpenny, D. M. Kane, R. N. Lamb, and B. Gong, "Surface modification of silica with ultraviolet laser radiation," Applied Physics A, vol. 71, no. 2, pp. 147-151, 2000.

[5] K. Seiichi, H. Yamamuchi, Y. Kajiyama, and T. Ishikawa, "Physical and chemical properties of inactive surface hydrogen-bonded hydroxyl groups," Journal of the Chemical Society, vol. 80, no. 1, pp. 2033-2038, 1984.

[6] M. L. Hair, Infrared Spectroscopy in Surface Chemistry, Marcel Dekker, New York, NY, USA, 1967.

[7] L. H. Little, Infrared Spectra of Adsorbed Species, Academic press, London, UK, 1966.

[8] J. M. Haynes, "Porous media: structures and models," in Colloid Science Vol. 2. Specialist Periodical Report, Chemical Society, London, UK, 1975.

[9] P. B. Sarawade, J. K. Kim, A. Hilonga, and H. T. Kim, "Preparation of hydrophobic mesoporous silica powder with a high specific surface area by surface modification of a wetgel slurry and spray-drying," Powder Technology, vol. 197, no. 3, pp. 288-294, 2010.

[10] X. K. Ma, N. H. Lee, H. J. Oh et al., "Surface modification and characterization of highly dispersed silica nanoparticles by a cationic surfactant," Colloids and Surfaces A, vol. 358, no. 1-3, pp. 172-176, 2010.

[11] Q. J. He, X. Z. Li, and D. Y. Meng, "Long-chain alkylsilanemodified porous silica beads as gpc packings," Journal of Liquid Chromatography, vol. 5, no. 7, pp. 1223-1239, 1982.

[12] X. Li, J. Pennington, J. F. Stobaugh, and C. Schöneich, "Synthesis of sulfonamide- and sulfonyl-phenylboronic acidmodified silica phases for boronate affinity chromatography at physiological pH," Analytical Biochemistry, vol. 372, no. 2, pp. 227-236, 2008.

[13] X. D. Liu, A. V. Bordunov, and C. A. Pohl, "Preparation and evaluation of a hydrolytically stable amide-embedded stationary phase," Journal of Chromatography A, vol. 1119, no. 1-2, pp. 128-134, 2006.

[14] C. C. Chu, N. Ueno, and T. Imae, "Solid-phase synthesis of amphiphilic dendron-surface-modified silica particles and their application toward water purification," Chemistry of Materials, vol. 20, no. 8, pp. 2669-2676, 2008.

[15] A. F. Scott, J. E. Gray-Munro, and J. L. Shepherd, "Influence of coating bath chemistry on the deposition of 3-mercaptopropyl trimethoxysilane films deposited on magnesium alloy," Journal of Colloid and Interface Science, vol. 343, no. 2, pp. 474-483, 2010.

[16] S. Radi, A. Attayibat, A. Ramdani, and M. Bacquet, "Surface modification of porous silica with bi-thiophene tripodal ligand and aplication to adsorption of toxic metal cations," 
Phosphorus, Sulfur and Silicon and the Related Elements, vol. 185, no. 1, pp. 232-241, 2010.

[17] M. A. Natal-Santiago and J. A. Dumesic, "Microcalorimetric, FTIR, and DFT studies of the adsorption of methanol, ethanol, and 2,2,2-trifluoroethanol on silica," Journal of Catalysis, vol. 175, no. 2, pp. 252-268, 1998.

[18] M. Seman, J. N. Kondo, K. Domen, and S. T. Oyama, "Spillover and migration of alkoxy groups formed by adsorption of alcohols on silica-supported molybdenum oxide," Chemistry Letters, no. 11, pp. 1082-1083, 2002.

[19] M. Mizukami and K. Kurihara, "Alcohol cluster formation on silica surfaces in cyclohexane," Progress in Colloid and Polymer Science, vol. 117, pp. 13-17, 2001.

[20] M. S. Nadiye-Tabbiruka, "Characterization of the silica surface. I Characterization of modified aerosil by using adsorption of benzene," Colloid and Polymer Science, vol. 281, no. 1, pp. 36-44, 2003.

[21] R. J. Ward, A study of the effect of heat treatment on the physical properties of carbon black [Ph.D. thesis], University of Bristol, Bristol, UK, 1984.

[22] J. C. Morgan, [Ph.D. thesis], University of Bristol, Bristol, UK, 1976.

[23] M. S. Nadiye-Tabbiruka, "The kinetics of silylation of hydroxylated silica II CPG-10 porous glasses," Colloid and Polymer Science, vol. 278, no. 7, pp. 677-681, 2000.

[24] M. S. Nadiye-Tabbiruka, "Characterization of porous silica. 2. CPG-10 (VYCOR)," Colloid and Polymer Science, vol. 282, no. 9, pp. 1049-1053, 2004.

[25] S. Brunauer, L. S. Deming, W. E. Deming, and E. Teller, "On a theory of the van der Waals adsorption of gases," Journal of The American Chemical Society, vol. 62, no. 7, pp. 1723-1732, 1940.

[26] K. S. W. Sing, "Reporting physisorption data for gas/solid systems with special reference to the determination of surface area and porosity," Pure and Applied Chemistry, vol. 54, no. 11, pp. 2201-2218, 1982.

[27] V. Ya Davydov, A. V. Kiselev, and V. I. Lygin, "Infrared study of the adsorption of trimethylcarbinol on aerosil," Russian Journal of Physical Chemistry, vol. 37, p. 243, 1963.

[28] I. Y. Babkin, "Effects of degree of modification of the surface of silica by (CH3)3SiCl on the adsorption properties," Doklady Akademii Nauk SSSR, vol. 129, p. 131, 1959.

[29] G. V. Rakhmatkariev, Kh. R. Zhalalov, and K. S. Akhmedov, "Calorimetric study of adsorption of gases on silicalite," Uzbekskii Khimicheskii Zhurnal, vol. 3, pp. 68-70, 1988.

[30] I. Y. Babkin and A. V. Kiselev, "Adsorption and heats of adsorption of different vapours on aerosil surfaces modified by trimethylsilyl groups," Russian Journal of Physical Chemistry, vol. 36, no. 1326, 1962.

[31] Y. Teraoka, S. Ishida, A. Yamasaki et al., "Synthesis and characterization of tin oxide-modified mesoporous silica by the repeated post-grafting of tin chloride," Microporous and Mesoporous Materials, vol. 48, no. 1-3, pp. 151-158, 2001.

[32] Z. Qian, G. Hu, S. Zhang, and M. Yang, "Preparation and characterization of montmorillonite-silica nanocomposites: a sol-gel approach to modifying clay surfaces," Physica B, vol. 403, no. 18, pp. 3231-3238, 2008.

[33] K. Kailasam, A. Fels, and K. Müller, "Octadecyl grafted MCM-41 silica spheres using trifunctionalsilane precursorspreparation and characterization," Microporous and Mesoporous Materials, vol. 117, no. 1-2, pp. 136-147, 2009.
[34] L. Wang, A. Lu, Z. Xiao, J. Ma, and Y. Li, "Modification of nano-fibriform silica by dimethyldichlorosilane," Applied Surface Science, vol. 255, no. 17, pp. 7542-7546, 2009.

[35] M. Odlyha, S. O. Akapo, and C. F. Simpson, "DSC study of chemically modified porous silica powders," Thermochimica Acta C, vol. 134, pp. 457-461, 1988.

[36] L. Alzamora, S. Contreras, and J. Cortés, "Surface methylation of aerosil and its influence on the adsorption of water," Journal of Colloid And Interface Science, vol. 50, no. 3, pp. 503-507, 1975.

[37] E. F. Hare and W. A. Zisman, "Autophobic liquids and the properties of their adsorbed films," Journal of Physical Chemistry, vol. 59, p. 335, 1955.

[38] D. Basmadjian and K. P. Chu, "On the pore structure of vycor glass," Canadian Journal of Chemistry, vol. 42, p. 946, 1964.

[39] M. S. Nadiye-Tabbiruka, Organically modified silica surfaces, kinetics models and properties [Ph.D. thesis], University of Bristol, Bristol, UK, 1991. 


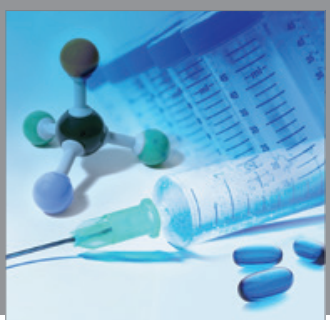

International Journal of

Medicinal Chemistry

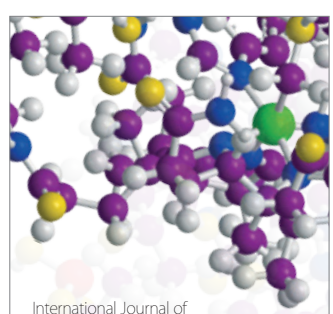

Carbohydrate Chemistry

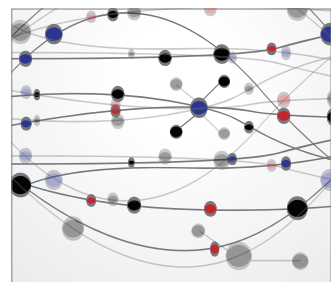

The Scientific World Journal
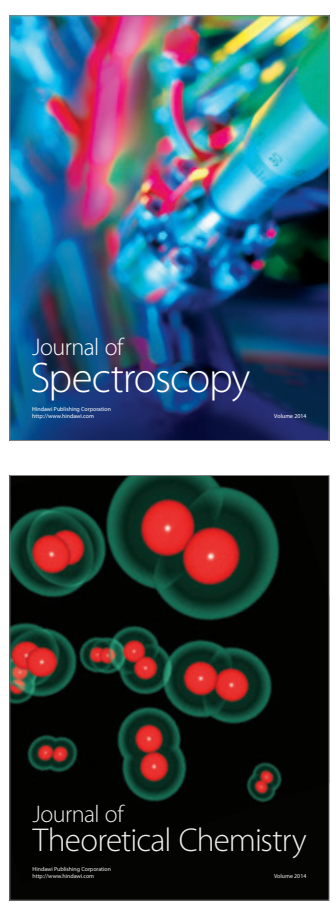
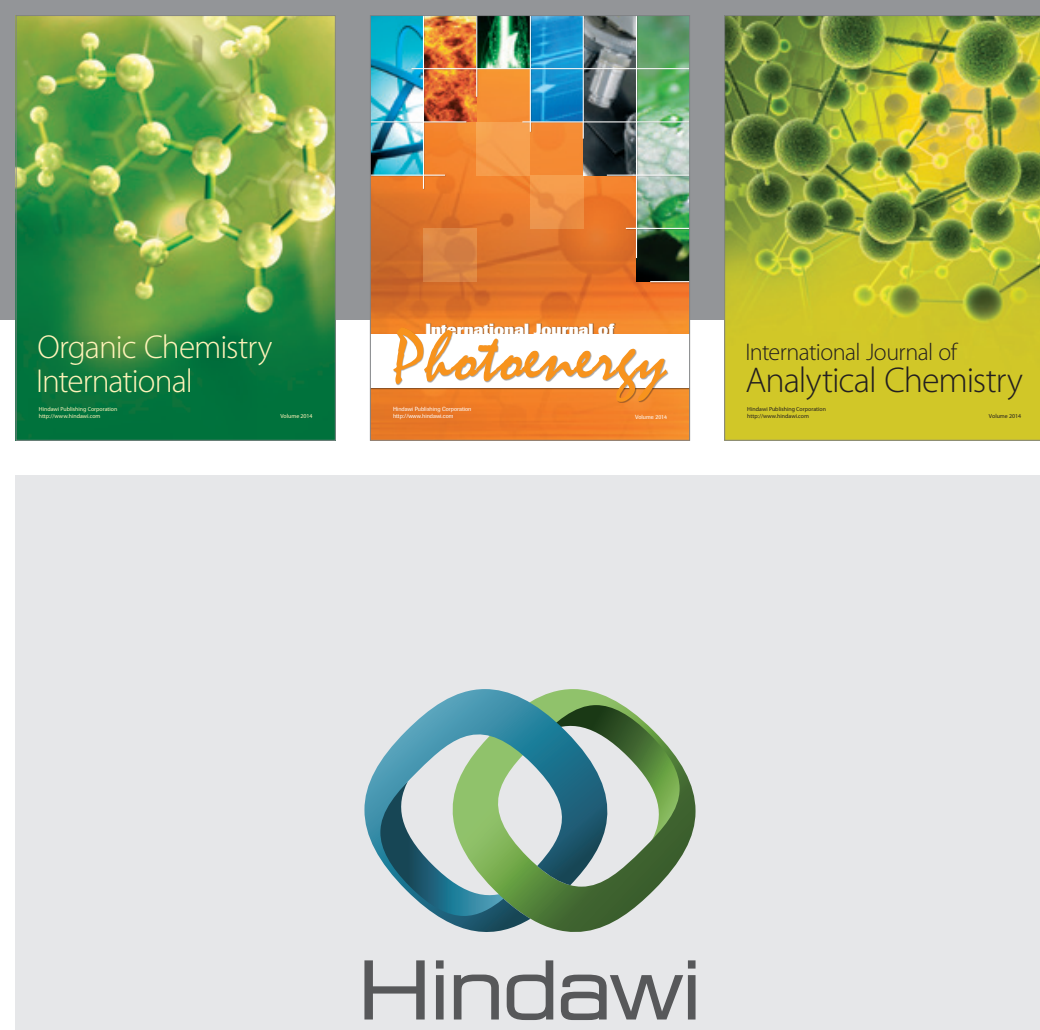

Submit your manuscripts at

http://www.hindawi.com
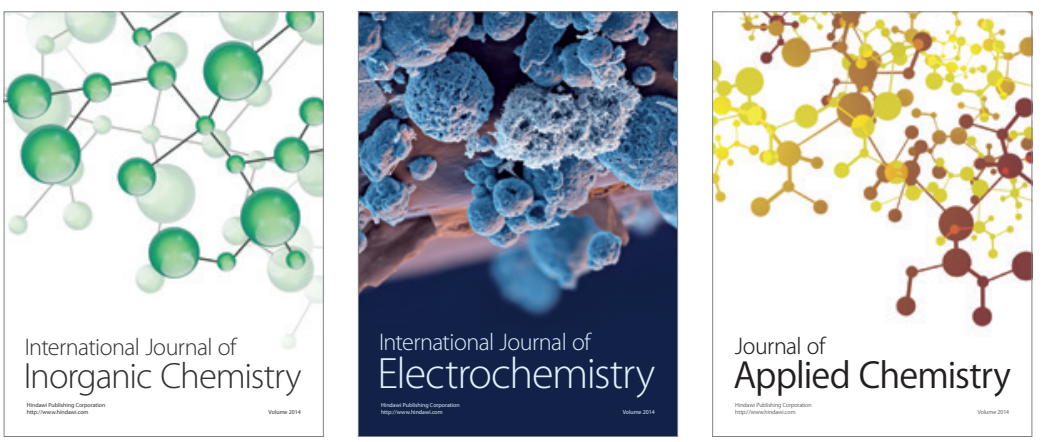

Journal of

Applied Chemistry
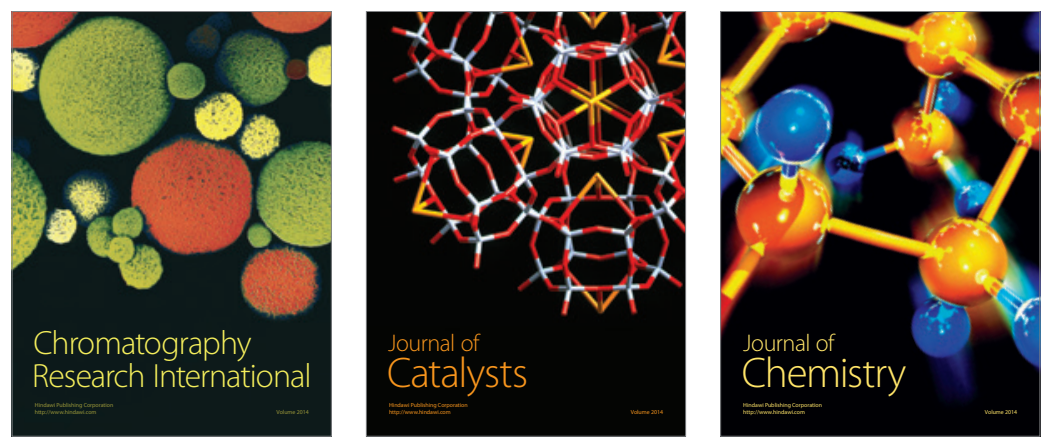
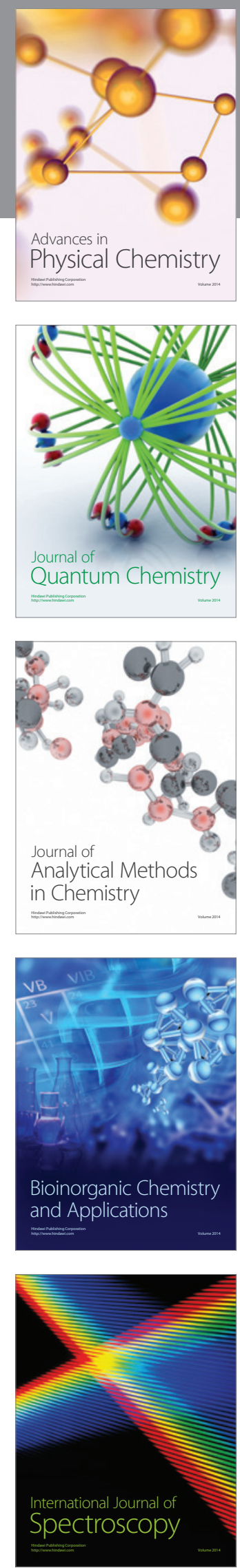